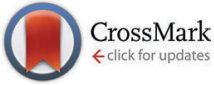

Cite this: Chem. Commun., 2016, 52,5694

Received 22nd February 2016, Accepted 18th March 2016

DOI: $10.1039 / \mathrm{c} 6 \mathrm{cc} 01614 f$

www.rsc.org/chemcomm

\section{A mechano- and thermoresponsive luminescent cyclophane $\dagger$}

\author{
Yoshimitsu Sagara, ${ }^{a \mathrm{~b}}$ Yoan C. Simon, ${ }^{\mathrm{bc}}$ Nobuyuki Tamaoki ${ }^{\mathrm{a}}$ and Christoph Weder ${ }^{\star \mathrm{b}}$
}

\begin{abstract}
The first fluorescent cyclophane with mechano- and thermoresponsive solid-state fluorescence characteristics is reported. The new cyclophane comprises two 9,10-bis(phenylethynyl)anthracene moieties that are bridged by tetraethylene glycol spacers. The stimuliresponsiveness is based on molecular assembly changes.
\end{abstract}

The last decade has witnessed a continuously increasing number of studies on materials where mechanical force leads to the controlled cleavage of stable ${ }^{1,2}$ or dynamic ${ }^{3}$ covalent bonds, or the dissociation of supramolecular motifs. ${ }^{4}$ This general mechanism is useful for the design of stimuli-responsive materials, whose properties can be altered upon application of mechanical forces. If the forceinduced separation involves mechanically active motifs (referred to as mechanophores) with extended $\pi$-conjugated groups, changes of the material's absorption and/or photoluminescence properties occur. ${ }^{1,2}$ Especially, the latter can be easily detected, making mechanically responsive (luminescent) color-changing materials potentially useful, for example in the in situ monitoring of material failure due to stress fracture or fatigue. ${ }^{5}$ However, the number of luminophores whose photophysical properties can be altered by mere dissociation of covalent or non-covalent bonds is still limited and few generally applicable design principles have been established. ${ }^{1 b-e, 2}$

Mechanical forces can also be exploited to induce changes of molecular arrangements, and a large number of mechanoresponsive luminescent (MRL) materials have been reported, which change their emission characteristics upon mechanical stimulation. $^{2,6-8}$ A most effective strategy to create MRL materials is to design

\footnotetext{
${ }^{a}$ Research Institute for Electronic Science, Hokkaido University, N20, W10, Kita-Ku, Sapporo 001-0020, Japan. E-mail: sagara@es.hokudai.ac.jp

${ }^{b}$ Adolphe Merkle Institute, University of Fribourg, Chemin des Verdiers 4, CH-170O Fribourg, Switzerland. E-mail: christoph.weder@unifr.ch

${ }^{c}$ School of Polymers and High Performance Materials, the University of Southern Mississippi, 118 College Dr. \#5050, Hattiesburg, MS, 39406, USA

$\dagger$ Electronic supplementary information (ESI) available: Synthesis and characterization data of compounds $\mathbf{1}$ and 2, NMR, DSC, TG, XRD, grinding procedure, precipitation of $\mathbf{1}$ from other solvent combinations, emission lifetime measurements, absorption and emission spectra of $\mathbf{1}$ and $\mathbf{2}$ under various conditions. See DOI: $10.1039 / \mathrm{c} 6 \mathrm{cc} 01614 \mathrm{f}$
}

luminescent molecules so they can assemble in different thermodynamically (meta)stable states, in which they adopt different conformations and/or intermolecular interactions. ${ }^{6 d}$ Organic molecules of various shapes - from rods to fan or dumbbell shapes - have been demonstrated to form assemblies with MRL properties. ${ }^{2,6-8}$ Here we report the first fluorescent cyclophane with mechano- and thermoresponsive solid-state fluorescence characteristics. While the properties of cyclic compounds have been widely studied in solution, ${ }^{9}$ their stimuli-responsive photophysical properties in the solid state were little explored. Our study demonstrates that simple cyclic structures are useful to induce several thermodynamically (meta)stable states, presumably on account of spatial restrictions that prevent the luminophores to assemble in thermodynamically most stable closed-packed structures. We expect that the findings can be generalized and that the MRL feature may be readily imparted to other luminescent motifs by converting into cyclic structures.

Cyclophane 1 (Fig. 1) was designed to feature two 9,10-bis(phenylethynyl)anthracene moieties, as these chromophores (in their nonconnected state) are known to exhibit strong green fluorescence in good solvents. ${ }^{10}$ Flexible tetraethylene glycol linkers were chosen to connect the peripheral phenyl rings of two 9,10-bis(phenylethynyl)anthracene moieties to serve as bridge. Because of its cyclic

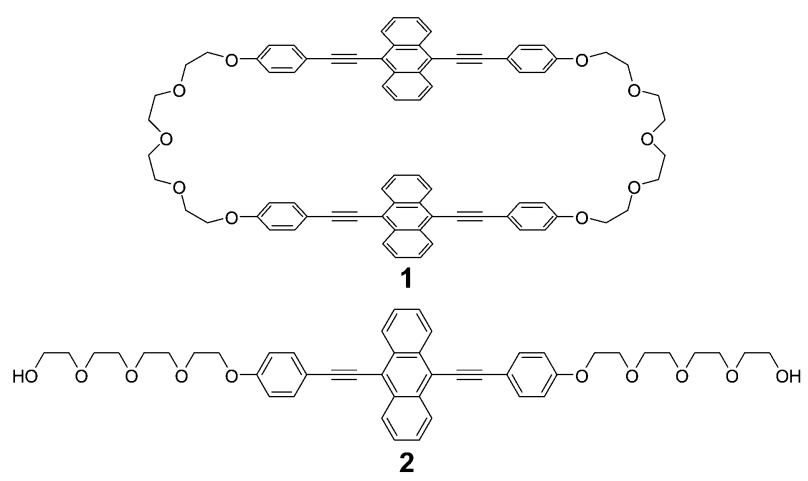

Fig. 1 Molecular structures of cyclophane 1 and the linear reference compound 2 
structure, compound $\mathbf{1}$ was expected to show intramolecular excimer formation and/or exciton coupling between the two luminescent cores in the molecularly isolated state. In the solid state, intra- and intermolecular interactions between the luminophores were expected to occur, which should independently affect the photophysical properties of the resulting molecular material. The linear mono-9,10-bis(phenylethynyl)anthracene 2 was also prepared and used as a reference compound.

Despite the tetraethylene glycol linkers, cyclophane 1 shows a low solubility in common organic solvents, presumably due to the rigid structure and strong $\pi-\pi$ interactions between molecules. NMR spectroscopic measurements were, however, possible after dissolution in hot chloroform. A comparison of the ${ }^{1} \mathrm{H}$ NMR spectra of $\mathbf{1}$ and 2 (Fig. S1, ESI $\dagger$ ) reveals an up-field shift of the resonances of the luminescent cores for cyclophane 1 ( 0.46 and $0.49 \mathrm{ppm}$ for the outer and inner protons of the anthracene groups, respectively), indicative of the formation of a cyclic structure, which changes the circular current. Together with the mass spectroscopy data, the large difference clearly confirms the success of the cyclization reaction (Scheme S1, ESI $\dagger$ ).

Spectroscopic measurements of $\mathbf{1}$ and $\mathbf{2}$ were first carried out in dilute $\left(1 \times 10^{-5} \mathrm{M}\right)$ chloroform solutions (Fig. 2). The absorption bands between 400 and $500 \mathrm{~nm}$ (Fig. 2a) show similar features, but upon closer inspection subtle differences can be discerned. While the spectrum of 1 displays two peaks at 446 and $473 \mathrm{~nm}$, these are observed at 450 and $471 \mathrm{~nm}$ in the case of 2 . Moreover, the magnitude of the two transitions is almost identical in $2(\varepsilon=3.7 \times$ $\left.10^{4} \mathrm{~L} \mathrm{~mol}^{-1} \mathrm{~cm}^{-1}\right)$, whereas in 1 the molar absorption coefficient at $446 \mathrm{~nm}\left(\varepsilon=5.7 \times 10^{4} \mathrm{~L} \mathrm{~mol}^{-1} \mathrm{~cm}^{-1}\right)$ is larger than that at $473 \mathrm{~nm}$ $\left(\varepsilon=4.7 \times 10^{4} \mathrm{~L} \mathrm{~mol}^{-1} \mathrm{~cm}^{-1}\right)$. The difference in spectral shape seen in the absorption spectra of $\mathbf{1}$ and $\mathbf{2}$ and the fact that the extinction

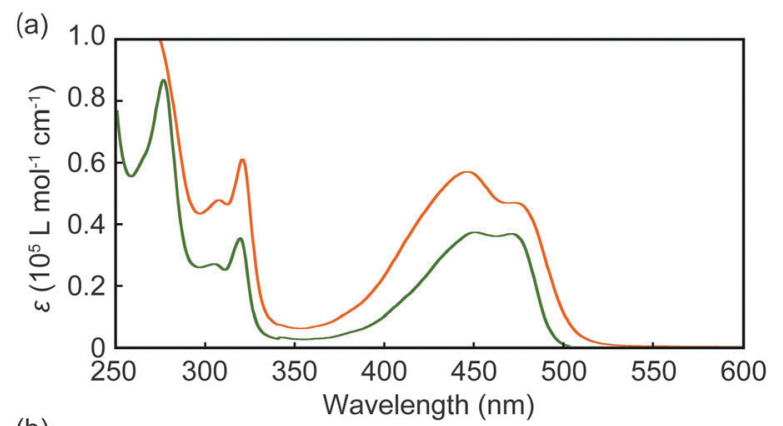

(b)

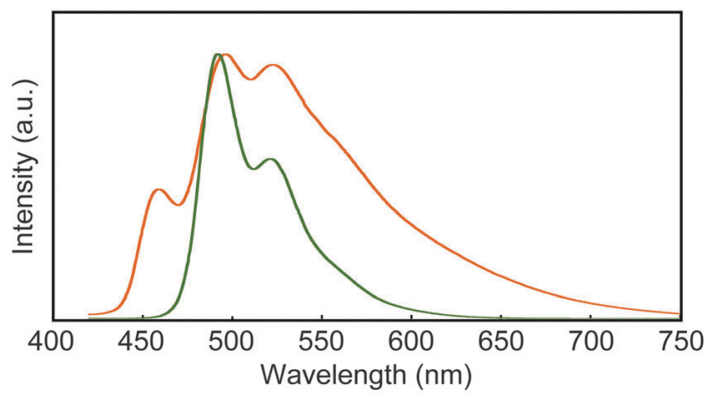

Fig. 2 Absorption (a) and emission (b) spectra of dilute $\left(1 \times 10^{-5} \mathrm{M}\right)$ chloroform solutions of cyclophane 1 (orange line) and the linear reference compound $\mathbf{2}$ (green line). All spectra were measured at room temperature. The emission spectra were recorded with $\lambda_{\mathrm{ex}}=400 \mathrm{~nm}$ and intensities were normalized coefficients of $\mathbf{1}$ are only slightly (and not two times) higher than those of $\mathbf{2}$ are the first indication of intramolecular, ground-state electronic interactions between two luminophores in $\mathbf{1}$.

In dilute $\left(1 \times 10^{-5} \mathrm{M}\right)$ chloroform solution, 2 is highly emissive and the emission spectrum reveals a vibronic structure with maxima at 492 and $522 \mathrm{~nm}$ (Fig. 2b). These features are characteristic of wellindividualized 9,10-bis(phenylethynyl)anthracene molecules in a good solvent. ${ }^{10 a, c} \mathrm{~A}$ much lower emission intensity was observed when 1 was excited under identical conditions. The emission spectrum (Fig. 2b) shows an extra vibronic band at higher energy $(459 \mathrm{~nm})$ and a pronounced shoulder that stretches far into the red. The latter is indicative of intramolecular excimer formation, ${ }^{11}$ which has also been observed in the case of pyrene- or perylene-based cyclophanes, i.e., in cases where the planar luminophores can form face-to-face stacked structures. ${ }^{12,13}$

To unravel the emission characteristics of $\mathbf{1}$ and $\mathbf{2}$ in solution, we measured the excited state lifetimes $(\tau)$ and photoluminescence quantum yields $\left(\Phi_{\mathrm{PL}}\right)$ in chloroform (Table S1, ESI $\dagger$ ). Fig. S2 (ESI $\dagger$ ) shows time-resolved emission decay profiles for both 1 and 2. In the case of 2 , the decay curve is well fitted by a single exponential decay function with a lifetime of $2.9 \mathrm{~ns}$ (Fig. S2a, ESI $\dagger$ ), characteristic of wellindividualized chromophores. The emission decay of $\mathbf{1}$ was measured at 495 and $600 \mathrm{~nm}$ (Fig. S2b, ESI $\dagger$ ). In both cases, multi-exponential decay functions fitted the data. The decay curve collected at $600 \mathrm{~nm}$ comprises a minor component with a lifetime of 8.8 ns that is ascribed to intramolecular excimers. By contrast, the longest emission lifetime observed at $495 \mathrm{~nm}$ was $5.8 \mathrm{~ns}$, which can be attributed to monomer emission after dissociation of intramolecular excimers. At both wavelengths, the emission lifetime related to monomer (2.6 ns) is shorter than in the case of 2, on account of the formation of intramolecular excimers. The fastest decay process with emission lifetimes of 0.3 and $0.2 \mathrm{~ns}$ at 495 and $600 \mathrm{~nm}$ respectively is likely associated with exciton coupling between adjacent luminophores in the cyclophane. Indeed, as shown in Fig. 2a, the molar absorption coefficient at $446 \mathrm{~nm}$ is larger than that at $473 \mathrm{~nm}$, which is indicative of exciton coupling with H-type geometry, although the precise conformation of $\mathbf{1}$ in chloroform is unclear. Aside from minor internal reabsorption features, the emission and absorption spectra of 1 remained unchanged when the concentration in chloroform was reduced from $10^{-5}$ to $10^{-6}$ (absorption) or $10^{-7} \mathrm{M}$ (emission) (Fig. S3, ESI $\dagger$ ), confirming that the observed exciton coupling is an intramolecular process and does not arise from the aggregation of cyclophane 1. This interpretation is further supported by the fact that previously reported perylene-based cyclophanes also exhibit absorption bands that correspond to H-type exciton coupling, ${ }^{13}$ and the additional high-energy emission peak at $459 \mathrm{~nm}$ (vide supra). While radiative relaxation from the higher energy level resulting from the splitting of the lowest unoccupied molecular orbital of the monomer species is forbidden in an ideal H-aggregate geometry, the twisted arrangement of transition dipole moments allows the direct decay process from the higher and forbidden energy level to some extent. ${ }^{14}$ Our interpretation of the emission decay profiles is further supported by quantum yield measurements. Indeed, the photoluminescence quantum yield of 1 in chloroform $\left(\Phi_{\mathrm{PL}}=0.07\right)$ is much lower than that of $2\left(\Phi_{\mathrm{PL}}=0.90\right)$, on account of intramolecular excimer formation and exciton coupling in the cyclophane. 


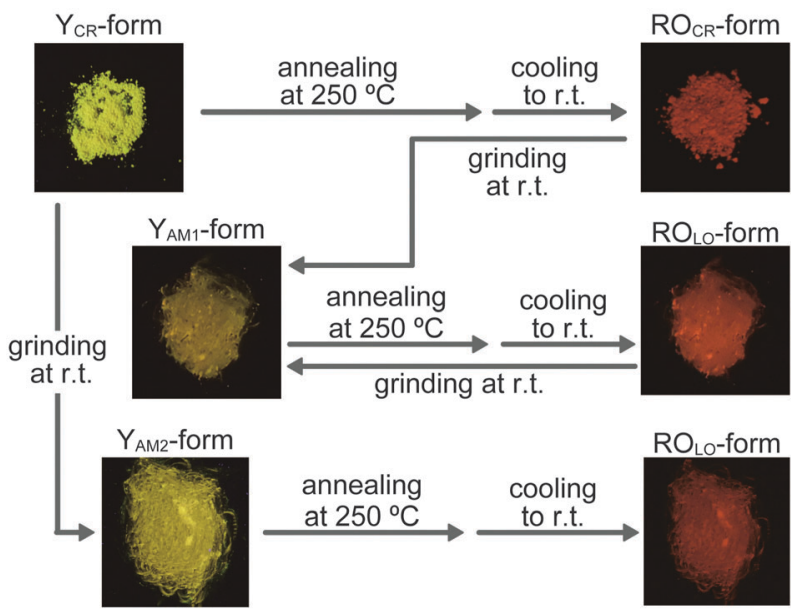

Fig. 3 Thermo- and mechanoresponsive luminescence behavior of 1 with pictures showing the emission color in each state. All pictures were taken under UV irradiation $\left(\lambda_{\mathrm{ex}}=365 \mathrm{~nm}\right)$ at room temperature.

The thermo- and mechanoresponsive luminescent behavior of $\mathbf{1}$ is summarized in Fig. 3. Upon precipitating $\mathbf{1}$ from a hot concentrated chloroform solution into hexane, a yellow-light emitting crystalline powder $\left(\mathrm{Y}_{\mathrm{CR}}\right.$-form) is formed, while other solvent combinations typically afforded orange-yellow emissive powders (Fig. S4, ESI $\dagger$ ). We found that a transition to another crystalline form that exhibits reddish-orange photoluminescence $\left(\mathrm{RO}_{\mathrm{CR}^{-}}\right.$-form) can be achieved by annealing the $\mathrm{Y}_{\mathrm{CR}^{-}}$-form for $10 \mathrm{~min}$ at $250{ }^{\circ} \mathrm{C}$. While 1 displayed thermoresponsive luminescent characteristics, this behavior was not observed for $\mathbf{2}$ in the solid state. Moreover, $\mathbf{1}$ shows mechanochromic luminescence behavior. Grinding of the $\mathrm{RO}_{\mathrm{CR}}$-form leads to an amorphous state showing yellow photoluminescence ( $\mathrm{Y}_{\mathrm{AM} 1}$-form). Subsequent annealing at $250{ }^{\circ} \mathrm{C}$ for $10 \mathrm{~min}$ largely restored the reddish-orange emission color $\left(\mathrm{RO}_{\mathrm{LO}}\right.$-form), although the molecular packing appears to be less-ordered (LO) than in the $\mathrm{RO}_{\mathrm{CR}^{-}}$-form. Grinding the $\mathrm{Y}_{\mathrm{CR}}$-form leads to another amorphous state $\left(\mathrm{Y}_{\mathrm{AM} 2^{-}}\right.$ form), whose emission spectrum is slightly different from that of the $\mathrm{Y}_{\mathrm{AM} 1}$-form (vide infra). However, subsequent annealing also caused the conversion to $\mathrm{RO}_{\mathrm{LO}}$-form. While various molecular structures have been found to show thermo- or mechanoresponsive luminescence, $^{2,6-8,15}$ compound 1, to our knowledge, is the first reported cyclophane exhibiting such behavior.

Powder X-ray diffraction (XRD) patterns of $\mathbf{1}$ (Fig. S5, ESI $\dagger$ ) clearly reveal that the emission color changes induced by thermal or mechanical treatment result from alterations of the molecular packing. The XRD pattern obtained for the $\mathrm{Y}_{\mathrm{CR}^{-}}$form (Fig. S5a, $\mathrm{ESI} \dagger$ ) displays many diffraction peaks that reflect the crystalline nature of this form. The diffractogram changes substantially upon annealing the sample for $10 \mathrm{~min}$ at $250{ }^{\circ} \mathrm{C}$ (Fig. S5b, ESI $\dagger$ ). Thus, the thermal treatment causes a solid-solid phase transition between two different crystal structures, which is responsible for the emission color change from the $\mathrm{Y}_{\mathrm{CR}^{-}}$-form to the $\mathrm{RO}_{\mathrm{CR}^{-}}$-form. The phase transition was confirmed by differential scanning calorimetry (DSC). The DSC trace of the $\mathrm{Y}_{\mathrm{CR}}$-form displays an endothermic peak $\left(\Delta H=4.4 \mathrm{~kJ} \mathrm{~mol}^{-1}\right)$ at $221{ }^{\circ} \mathrm{C}$ (Fig. S6a, ESI $\dagger$ ), which we associate with the transition to the $\mathrm{RO}_{\mathrm{CR}}$-form. By contrast, the DSC curve measured for the $\mathrm{RO}_{\mathrm{CR}^{-}}$-form
(Fig. S6a, ESI $\dagger$ ) is void of this and any other characteristic signals. Thermogravimetric analysis experiments of 1 (Fig. S7, ESI $\dagger$ ) show no significant weight loss below $300{ }^{\circ} \mathrm{C}$ and confirm that the transition from the $\mathrm{Y}_{\mathrm{CR}}$-form to the $\mathrm{RO}_{\mathrm{CR}}$-form is not due to the release of trapped solvent. Compound 2 could not be converted into a reddishorange emissive state, indicating that cyclization is the key to the stimuli-responsive behavior of $\mathbf{1}$.

The powder XRD patterns of both grinding-induced, amorphous forms ( $\mathrm{Y}_{\mathrm{Am} 1}$-form and $\mathrm{Y}_{\mathrm{AM} 2}$-form) are void of any diffraction peaks (Fig. S5c and e, ESI $\dagger$ ), suggesting that grinding induces conversions from crystalline to amorphous states. Annealing of both amorphous forms for $10 \mathrm{~min}$ at $250{ }^{\circ} \mathrm{C}$ caused restoration of some of the peaks in the XRD ( $\mathrm{RO}_{\mathrm{LO}}$-form, Fig. S5d and $\left.\mathrm{f}, \mathrm{ESI} \dagger\right)$, which appear at similar spacings as observed for the $\mathrm{RO}_{\mathrm{CR}}$-form. Taking into account the fact that the emission spectrum is similar to that of the $\mathrm{RO}_{\mathrm{CR}}$-form (vide infra), we conclude that the thermal treatment restores a molecular assembly that is similar to the $\mathrm{RO}_{\mathrm{CR}}$-form. However, the intensities of the peaks observed in the diffractogram of the $\mathrm{RO}_{\mathrm{LO}}$-form are much lower than observed for $\mathrm{RO}_{\mathrm{CR}}$-form, and the DSC trace acquired upon heating the $\mathrm{Y}_{\mathrm{AM} 1}$-form is featureless (Fig. S6a, ESI $\dagger$ ), indicating that annealing of the amorphous form of $\mathbf{1}$ leads to assembled structures with limited degree of order.

The photophysical properties of $\mathbf{1}$ were also examined in the solid state. Fig. 4 shows the steady-state emission spectra of 1 . The spectra correspond well with the emission color observed by the unassisted eye (Fig. 3). The $\mathrm{Y}_{\mathrm{CR}^{2}}$-form and $\mathrm{RO}_{\mathrm{CR}^{-}}$-form display broad emission bands with maxima around 555 and $614 \mathrm{~nm}$, respectively. In contrast to the emission spectrum of 1 in chloroform, the solid-state spectra are broad and featureless. The emission band observed for the $\mathrm{RO}_{\mathrm{CR}}$-form is ascribed to static excimer formation of the 9,10-bis(phenylethynyl)anthracene cores. Gratifyingly, emission lifetime measurements support the formation of static excimers in the $\mathrm{RO}_{\mathrm{CR}}$-form. Fig. S8 (ESI $\dagger$ ) shows time-resolved fluorescent decays measured for $\mathrm{Y}_{\mathrm{CR}^{-}}$form and $\mathrm{RO}_{\mathrm{CR}}$-form at $600 \mathrm{~nm}$. The data are fitted well by a double exponential function, resulting in a long emission lifetime of $12.0 \mathrm{~ns}$ (Table S1, ESI $\dagger$ ). By contrast, the decay trace of the $\mathrm{Y}_{\mathrm{CR}}$-form is dominated by a component with a short lifetime of $0.8 \mathrm{~ns}$, which can be attributed to exciton coupling.

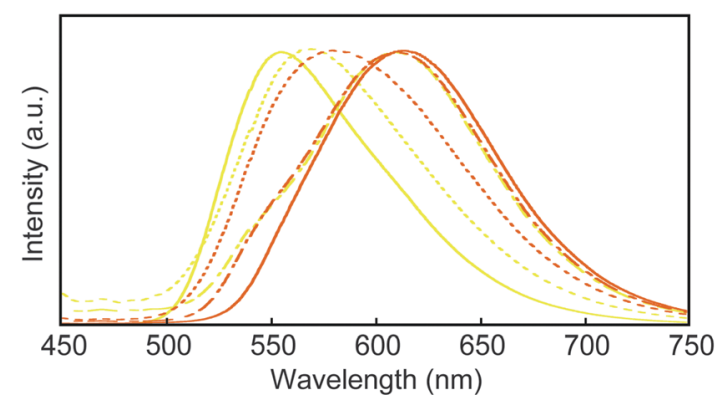

Fig. 4 Emission spectra of the $Y_{C R}$-form (yellow solid line), $R O_{C R}$-form (orange solid line), $Y_{A M 1}$-form (orange dotted line), $Y_{A M 2}$-form (yellow dotted line), $\mathrm{RO}_{\mathrm{LO}}$-form obtained from the $\mathrm{Y}_{\mathrm{AM} 1}$-form (orange dash-dotted line), and $\mathrm{RO}_{\mathrm{LO}}$-form obtained from the $\mathrm{Y}_{\mathrm{AM} 2}$-form (yellow dash-dotted line) of 1 measured at room temperature with $\lambda_{\mathrm{ex}}=400 \mathrm{~nm}$. 
In comparison to the $\mathrm{RO}_{\mathrm{CR}}$-form, the $\mathrm{Y}_{\mathrm{CR}^{-}}$-form features a much smaller proportion of excimer emission. The two crystalline states have a similar quantum yield of 0.4 (Table S1, ESI $\dagger$ ).

The emission spectra of the amorphous $\mathrm{Y}_{\mathrm{AM} 1}$-form and $\mathrm{Y}_{\mathrm{AM} 2}$-form of cyclophane $\mathbf{1}$ (Fig. 4) show maxima that are situated between those of the $\mathrm{Y}_{\mathrm{CR}^{-}}$-form and the $\mathrm{RO}_{\mathrm{CR}^{-}}$-form. The difference between the emission spectra of the two amorphous forms may be ascribed to a small amount of residual crystalline particles after grinding. In the case of the $\mathrm{Y}_{\mathrm{AM} 1}$-form, this would enable energy transfer to excimer sites from the parent $\mathrm{RO}_{\mathrm{CR}^{-}}$-form, leading to a slight red-shift of the emission band compared to that of the $\mathrm{Y}_{\mathrm{AM} 2}$-form. While it is, unfortunately, impossible to distinguish if the grinding process changes inter- or intramolecular arrangements of the emissive cores of $\mathbf{1}$, one can speculate that probably a broad range of species with different conformation is present in the two amorphous forms and that the optical properties change on account of alterations of both these factors. The emission spectrum of the $\mathrm{RO}_{\mathrm{LO}}$-form, which was obtained by annealing the $\mathrm{Y}_{\mathrm{AM} 1}$-form (Fig. 4), is very similar to that of $\mathrm{RO}_{\mathrm{CR}^{-}}$ form, although a small shoulder appears around $540 \mathrm{~nm}$. The emission spectrum of the $\mathrm{RO}_{\mathrm{LO}}$-form obtained from $\mathrm{Y}_{\mathrm{AM} 2}$-form also shows the same spectral feature (Fig. 4). This behavior is consistent with the results obtained from powder XRD measurements and confirms that the annealing procedure does not lead to the complete recovery of the well-ordered molecular assembled structures that were observed for $\mathrm{RO}_{\mathrm{CR}}$-form. However, it appears that in the $\mathrm{RO}_{\mathrm{LO}}$-form, energy transfer from excited states with higher energy to excimer sites is at play, so that the relatively poorly ordered material displays emission characteristics that are reminiscent of the highly ordered $\mathrm{RO}_{\mathrm{CR}}$-form. Compound 2 also shows a mechanically induced shift of the emission band (Fig. S9, ESI $\dagger$ ), which is however much less pronounced than the one observed in the case of cyclophane $\mathbf{1}$. The comparison clearly shows the benefit of integrating the luminescent motif in a cyclic structure.

In summary, the first mechano- and thermoresponsive luminescent cyclophane has been reported. The compound's optical properties in the solid state depend strongly on the morphology, which in turn can be influenced by mechanical and/or thermal treatment. Interpreting the results broadly, our study demonstrates that the integration of a fluorescent motif into a cyclic structure is a promising approach to design stimuli-responsive luminescent molecular materials. We expect our findings to be general and applicable to cyclophanes comprising other luminescent cores and/or spacers.

We thank Prof. T. Nakano for optical and thermal measurements, and Prof. Y. Urano for emission lifetime and quantum yield experiments. Y. S. is grateful for financial support from JSPS Postdoctoral Fellowships for Research Abroad. C. W. acknowledges support from the National Center of Competence in Research (NCCR) Bio-Inspired Materials, a research instrument of the Swiss National Science Foundation, the European Research Council (ERC-2011-AdG 291490-MERESPO), and the Adolphe Merkle Foundation.

\section{Notes and references}

1 (a) M. M. Caruso, D. A. Davis, Q. Shen, S. A. Odom, N. R. Sottos, S. R. White and J. S. Moore, Chem. Rev., 2009, 109, 5755-5798; (b) D. A. Davis, A. Hamilton, J. Yang, L. D. Cremar, D. Van Gough, S. L. Potisek, M. T. Ong, P. V. Braun, T. J. Martínez, S. R. White, J. S. Moore and N. R. Sottos, Nature, 2009, 459, 68-72; (c) G. R. Gossweiler, G. B. Hewage, G. Soriano, Q. Wang, G. W. Welshofer, X. Zhao and S. L. Craig, ACS Macro Lett., 2014, 3, 216-219; (d) Y. Chen, H. Zhang, X. Fang, Y. Lin, Y. Xu and W. Weng, ACS Macro Lett., 2014, 3, 141-145; (e) R. Göstl and R. P. Sijbesma, Chem. Sci., 2016, 7, 370-375.

2 (a) M. Teng, X. Jia, X. Chen and Y. Wei, Angew. Chem., Int. Ed., 2012, 51, 6398-6401; (b) Z. Ma, M. Teng, Z. Wang, S. Yang and X. Jia, Angew. Chem., Int. Ed., 2013, 52, 12268-12272.

3 A. M. Belenguer, G. I. Lampronti, D. J. Wales and J. K. M. Sanders, J. Am. Chem. Soc., 2014, 136, 16156-16166.

4 (a) D. W. R. Balkenende, S. Coulibaly, S. Balog, Y. C. Simon, G. L. Fiore and C. Weder, J. Am. Chem. Soc., 2014, 136, 10493-10498; (b) A. P. Haehnel, Y. Sagara, Y. C. Simon and C. Weder, Top. Curr. Chem., 2015, 369, 345-375.

5 (a) C. Weder, J. Mater. Chem., 2011, 21, 8235-8236; (b) C. Weder, Nature, 2009, 459, 45-46.

6 (a) Y. Sagara and T. Kato, Nat. Chem., 2009, 1, 605-610; (b) F. Ciardelli, G. Ruggeri and A. Pucci, Chem. Soc. Rev., 2013, 42, 857-870; (c) Z. Ma, Z. Wang, M. Teng, Z. Xu and X. Jia, ChemPhysChem, 2015, 16, 1811-1828; (d) Y. Sagara, S. Yamane, M. Mitani, C. Weder and T. Kato, Adv. Mater., 2016, 28, 1073-1095.

7 (a) Y. Sagara, T. Mutai, I. Yoshikawa and K. Araki, J. Am. Chem. Soc., 2007, 129, 1520-1521; (b) J. Kunzelman, M. Kinami, B. R. Crenshaw, J. D. Protasiewicz and C. Weder, Adv. Mater., 2008, 20, 119-122; (c) S.-J. Yoon, J. W. Chung, J. Gierschner, K. S. Kim, M.-G. Choi, D. Kim and S. Y. Park, J. Am. Chem. Soc., 2010, 132, 13675-13683; (d) G. Zhang, J. Lu, M. Sabat and C. L. Fraser, J. Am. Chem. Soc., 2010, 132, 2160-2162; $(e)$ Y. Dong, B. Xu, J. Zhang, X. Tan, L. Wang, J. Chen, H. Lv, S. Wen, B. Li, L. Ye, B. Zou and W. Tian, Angew. Chem., Int. Ed., 2012, 51, 10782-10785; $(f)$ S. Yagai, S. Okamura, Y. Nakano, M. Yamauchi, K. Kishikawa, T. Karatsu, A. Kitamura, A. Ueno, D. Kuzuhara, H. Yamada, T. Seki and H. Ito, Nat. Commun., 2014, 5, 4013; $(g)$ H.-J. Kim, D. R. Whang, J. Gierschner, C. H. Lee and S. Y. Park, Angew. Chem., Int. Ed., 2015, 54, 4330-4333; (h) Y. Sagara, A. Lavrenova, A. Crochet, Y. C. Simon, K. M. Fromm and C. Weder, Chem. - Eur. J., 2016, 22, 4374-4378.

8 (a) Y. Sagara and T. Kato, Angew. Chem., Int. Ed., 2008, 47, 5175-5178; (b) Y. Sagara and T. Kato, Angew. Chem., Int. Ed., 2011, 50, 9128-9132; (c) H. Li, Z. Chi, B. Xu, X. Zhang, X. Li, S. Liu, Y. Zhang and J. Xu, J. Mater. Chem., 2011, 21, 3760-3767; (d) Y. Sagara, T. Komatsu, T. Ueno, K. Hanaoka, T. Kato and T. Nagano, Adv. Funct. Mater., 2013, 23, 5277-5284; (e) Y. Sagara, T. Komatsu, T. Ueno, K. Hanaoka, T. Kato and T. Nagano, J. Am. Chem. Soc., 2014, 136, 4273-4280.

9 (a) T. Stangl, S. Bange, D. Schmitz, D. Würsch, S. Höger, J. Vogelsang and J. M. Lupton, J. Am. Chem. Soc., 2013, 135, 78-81; (b) S. Liu, D. Schmitz, S.-S. Jester, N. J. Borys, S. Höger and J. M. Lupton, J. Phys. Chem. B, 2013, 117, 4197-4203.

10 (a) C. A. Heller, R. A. Henry, B. A. McLaughlin and D. E. Bliss, J. Chem. Eng. Data, 1974, 19, 214-219; (b) P. Hanhela and D. B. Paul, Aust. J. Chem., 1984, 37, 553-559; (c) M. Levitus and M. A. GarciaGaribay, J. Phys. Chem. A, 2000, 104, 8632-8637.

11 L. Qiu, C. Zhu, H. Chen, M. Hu, W. He and Z. Guo, Chem. Commun., 2014, 50, 4631-4634.

12 (a) M. Inouye, K. Fujimoto, M. Furusyo and H. Nakazumi, J. Am. Chem. Soc., 1999, 121, 1452-1458; (b) H. Abe, Y. Mawatari, H. Teraoka, K. Fujimoto and M. Inouye, J. Org. Chem., 2004, 69, 495-504.

13 (a) J. Feng, Y. Zhang, C. Zhao, R. Li, W. Xu, X. Li and J. Jiang, Chem. - Eur. J., 2008, 14, 7000-7010; (b) K. E. Brown, W. A. Salamant, L. E. Shoer, R. M. Young and M. R. Wasielewski, J. Phys. Chem. Lett., 2014, 5, 2588-2593.

14 M. Kasha, H. R. Rawls and M. A. El-Bayoumi, Pure Appl. Chem., 1965, 11, 371-392.

15 A. Seeboth, D. Lötzsch, R. Ruhmann and O. Muehling, Chem. Rev., 2014, 114, 3037-3068. 